\title{
Regional Comprehensive Economic Partnership (RCEP) - The Geopolitical and Economic Implications on Malaysia
}

\author{
Wei Ying Chong ${ }^{1 *}$
}

\author{
${ }^{1}$ Department of Management, Faculty of Accountancy, Finance and Business. Tunku Abdul Rahman University College \\ 50932 Kuala Lumpur, Malaysia \\ *Corresponding author. Email: chongwy@tarc.edu.my
}

\begin{abstract}
Regional Comprehensive Economic Partnership (RCEP) is a regional multilateral free trade agreement between the Asia-Pacific nations of China, Japan, South Korea, Malaysia, Singapore, Indonesia, Thailand, Cambodia, Brunei, Laos, the Philippines, Myanmar, Vietnam, Australia and New Zealand. With the signed of RCEP among these fifteen countries, a world's largest trading bloc which covering nearly a third of the global economy is formed. Furthermore, the involvement of almost all the major East Asia trading nations has make RCEP significant in terms of its sheer scale. As an economic cooperation arrangement, RCEP will spur the partners continuing to deepen the economic integration between their economies. The question is being asked more and more, especially since the negotiations for the RCEP was successfully concluded in 15 Nov 2020, is RCEP really about trade or is it more concerned with the world's geopolitical climate? This paper focuses on geopolitical considerations associated with Malaysia's membership of RCEP and the economic implications on Malaysia SMEs. Malaysia stands to benefit, but must move forward positively in both its domestic organization and external negotiations to optimize its gains.
\end{abstract}

Keywords: Regional comprehensive economic partnership (RCEP), small and medium enterprises (SMEs), free trade agreements, Malaysia, ASEAN

\section{INTRODUCTION}

In this era of globalisation, Free Trade Agreements (FTAs) burgeons. As of Dec 2020, Malaysia has signed, or is negotiating, 17 Free Trade Agreements [1]. These Free Trade Agreements aim to establish long term cooperation in policy, with agendas of setting activities, and performing in trade, technology, society and political development [2].

"Trade is always political"[3]. Trade agreements have major political imperatives as the various parties strive to exert their influence. For instance, the RCEP which was successfully signed on 15th November 2020 [2] intends to achieve an economic cooperation partnership among the ASEAN member states and its 'Plus Six' partners: China, Japan, South Korea, Australia, New Zealand and India. Although India pulls out from RCEP in 2019, RCEP still has considerable geopolitical overtones and has formed the world's largest trading bloc encompassing the major Asian economies.

Many assume that RCEP will only affect the Multinational Enterprises but a closer look at the agreement will informed you otherwise $[4,5]$. The comprehensive framework of rule of origin in RCEP reinforce the value chains and production networks within the region which can be a booster to small and medium enterprises (SMEs). With the enhance of economic integration within the region, all the signatories of the RCEP agreement, including Malaysia, are looking at a considerably boosts of their total GDP in the coming years.

Malaysia has a natural advantage over other RCEP countries in terms of established trading links as well as experience in diplomacy within the region [6]. Both government and industrialists welcome the sign of RCEP with open arms. The questions now will be, what is the implications of RCEP on Malaysia in terms of geopolitical and economic? Is RCEP really about trade or is it more concerned with the world's geopolitical climate?

\subsection{Contribution}

This paper is one of the few studies which focuses on geopolitical considerations associated with Malaysia's membership of RCEP. It has also investigated the influence of RCEP agreement on Malaysia SMEs. Particularly, it focuses on the performance of Malaysia's SMEs as whether RCEP could promote Malaysia SMEs with its member's countries using literature review. Despite of some challenges with different rules of origin between ASEAN + 
1, Malaysia has a great opportunity in improving its SMEs among RCEP countries[5,7].

\subsection{Structure of this Paper}

The remaining of the paper is structured as follows. Section 2 reviews the establishment of the RCEP and its background. Section 3 presents a brief discussion on the scope of the RCEP. Then, follows with geopolitics impact of RCEP on Malaysia in Section 4. Section 5 presents a discussion on the economic implications of RCEP on Malaysia SMEs. Finally, section 6 presents the conclusion of the paper.

\section{BACKGROUND}

\subsection{Background of the RCEP Initiative}

The idea of having a free trade agreement to streamline and amalgamate regional value chain actives was first proposed at the Fourth East Asia Summit in October 2009 [7]. Two years later, an Association of Southeast Asian Nations (ASEAN)-centered regional FTA - RCEP was proposed and endorsed by ASEAN leaders in November 2011 ASEAN [7]. In November 2012 at Phnom Penh, Cambodia, at the 21st ASEAN Summit, the RCEP negotiations was launched. Relevant members were invited to develop guiding principles and objectives for negotiating the RCEP. Nevertheless, the negotiations only formally started in 2013 [7].

Initially, RCEP was negotiated by 16 countries, consisting of Asia-Pacific nations of India, China, Japan, South Korea, Malaysia, Singapore, Indonesia, Thailand, Cambodia, Brunei, Laos, the Philippines, Myanmar, Vietnam, Australia and New Zealand. Nevertheless, with the withdrawal of India in 2019, only 15 members signed RCEP in 15 Nov 2020. It is an effort of eight years of lengthy and arduous a strenuous negotiation. The signing only concluded after eight ministerial meetings, thirty-one rounds of negotiations and four summits. The RCEP is signed with a spirit of equal partnership, mutual respect, common interest, shared responsibility, and common benefit[8].

\subsection{The scope of the RCEP}

FTAs has enabled trade and tariff liberalization to progress significantly among the 15 RCEP members over the past decade but RCEP will further reduce tariff barriers and enhance trade liberalization. According to Ministry of International Trade and Industry (2020), the scope of the RCEP is listed at Table 1,

Table 1: The scope of RCEP

- Tariff elimination for trade in goods, including the related chapters of rules or origin, customs procedures, sanitary and phytosanitary measures, standards, technical regulations and conformity assessment procedures and trade remedies

- Liberalization of services sectors, including financial services, telecommunications services and movement of natural persons

- Promotion, facilitation, protection and liberalization of investment

- Competition policy (countries are allowed to implement national laws related to state-owned enterprises), intellectual property rights, electronic commerce and government procurement (no market access, only for information exchange and promotion of transparency measures),

- Economic and technical cooperation and SMEs

- Legal and institutional issues

Source: Ministry of International Trade and Industry, 2020

With the signed of RCEP agreement, member nations are expected to reduce both tariff and non-tariff barriers to trade progressively. The comprehensive rules of origin framework as well as strengthening intellectual property protection has greatly extended the scope of trade and investment liberalization. ASEAN and partner countries are 
able to broadening the market access via RCEP by maintaining commitments in trade of good and services, and rules of origin.

\section{THE GEOPOLITICS IMPACT of RCEP}

The fact that RCEP did not involve any European countries of the United States marks the end of American world leadership, and casts the limelight on the growing influence of China [9]. RCEP is a type of intergovernmental economic cooperation which will be dominated by political objective rather than economic objective [2,10]. Most of the ASEAN parties joined for altruistic trade reasons, but for the leading economies such as China, it is all about setting the agenda and making the rules [10]. In fact, China is a figurehead for RCEP by the diplomacy of numbers [3]. RCEP is an Asia Centric FTA.

Trade is facilitated by the progressive abolition of tariffs on more than ninety per cent of goods, as well as the simplification of customs procedures[11]. Furthermore, the regional value chain will be enhanced by the unification of rules of origin for almost all of Asia. A strong regional value chain will benefit the manufacturing sector of the region through diversification. A particular note should be taken that RCEP unlike other free trade agreement such as Comprehensive and Progressive Agreement for TransPacific Partnership (CPTPP), it only focus on foster trade within the region and defy itself from protectionist. towards third-party countries.

Unlike the new generation of European agreements, there are no rules regarding intellectual property, or social and environmental standards. Instead, Chinese practices had brought into RCEP an emphasis on improving the protection of personal data in e-commerce, without standardized regional standards for digital technology [12]. Furthermore, RCEP neither enforce data localization not mandate technology transfer.

The fact that the US is not a part of the RCEP signifies the start of a new China-centric order in the Asia pacific region[9]. With the launch of RCEP, the Asia Pacific region increasingly become the battle ground of US-China wrestles for soft influence. Malaysia has been a trade partner of both China and the US since a long time ago, and is expected to stay neutral and focus on the pursuit of closer economic relations between countries. Thus, from Malaysia's point of view, the importance of RCEP lies in providing possible pathways to the establishment of a free trade area of the Asia-Pacific, rather than geostrategic gravity.

\section{THE ECONOMIC IMPLICATIONS on MALAYSIA SMES}

In times of the ravaging COVID-19 pandemic which paralyzed economic activities worldwide, the signing of the RCEP Agreement is crucial in rebooting the regional economic. With the fact that RCEP has dedicated chapters on E-commerce, SMEs and rules of origin, businesses within the region are expected to be thrive and provide vibrancy to regional economics. Regional value supply chain which is vital to fuel regional economic growth in the post COVID-19 pandemic will be further enhance via vibrant business activities among the RCEP member nations.

The signing of the RCEP is anticipated to benefit Malaysia industries as the pact will lower both tariff and non-tariff barriers to entry for Malaysian goods and services in East Asia. Furthermore, the comprehensive rule of origin framework and trade facilitation enable Malaysia SMEs to cross share resources with the other 15 member nations' SMEs.

\subsection{SMEs in Malaysia}

In Malaysia, SMEs comprise more than 90 percent of business entities. Statistics showed that SMEs account for more than $95 \%$ of the total business establishments and contributed more than $65 \%$ of total employment in Malaysia [13]. With these figures, SMEs are considered the backbone, and the main catalyst, of economic development in Malaysia. However, different nations have different criteria for measuring the size of SMEs, based on their level of development [14]. The Myanmar SMEs are defined based on the capital outlay, production value and power usage [15] while the Indonesian SMES are defined based on asset and annual sales turnover [16]. Following is Figure 1 which define Malaysian SMEs based on annual sales turnover and number of employees. 


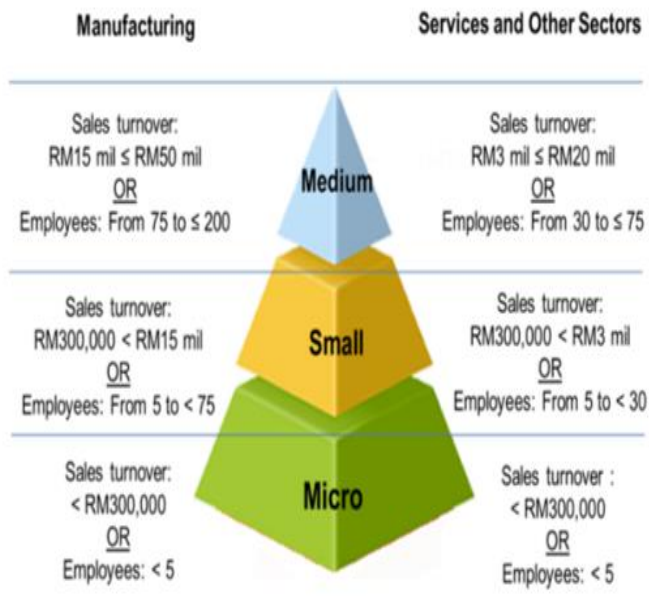

Figure 1: Malaysia SMEs definition Source: SME Corp. Malaysia

According to the definition, Malaysia SMEs' is highly concentrated in the services sector, at almost $90 \%$. Meanwhile, $5 \%$ of the total number of SMEs are in the manufacturing sector, followed by $4 \%$ in the construction sector, $1 \%$ in the agriculture sector, and $0.1 \%$ in the mining and quarrying sector. The details of the Profile of SMEs in Malaysia is presented in figure 2 .

\section{SMEs by Sector:}
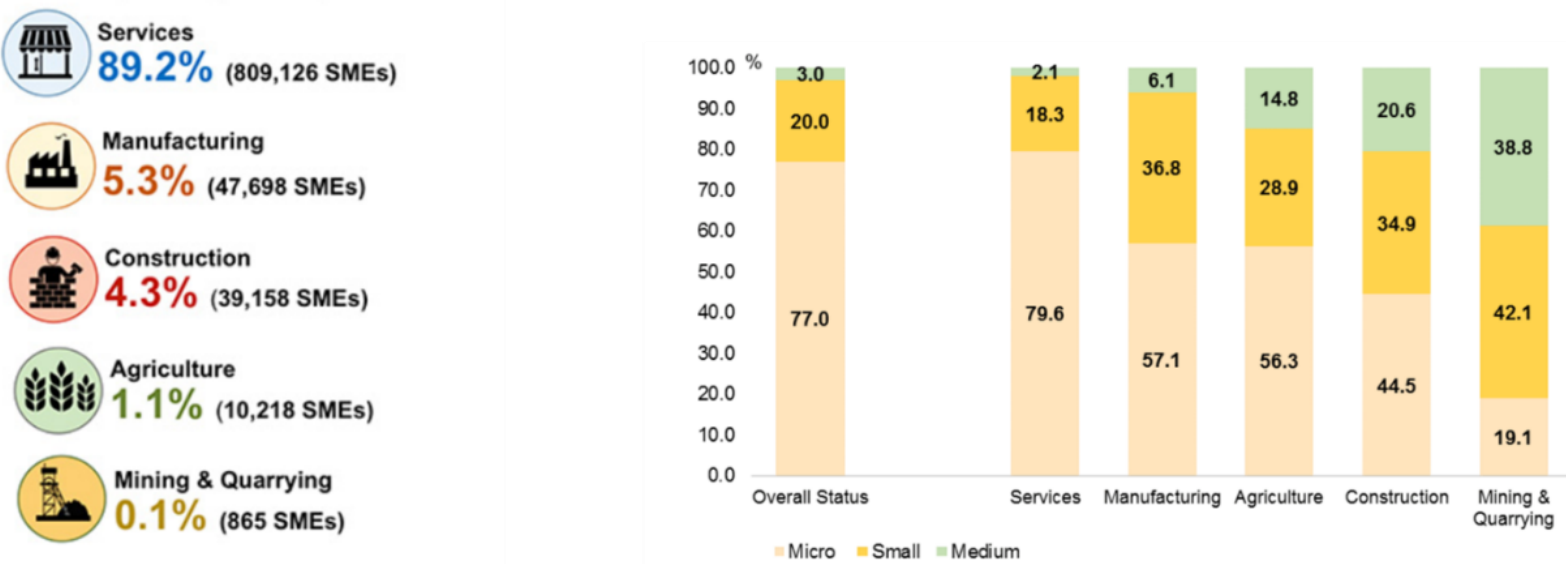

Figure 2: Profile of SMEs in malaysia Source: SME Corp. Malaysia

\subsection{Economic Implications}

As one of the biggest ASEAN lead trading blocs, RCEP encompasses 2.3 billion people, 30 percent of global gross domestic product (GDP), 32.5 percent global investment and $29 \%$ percent of global trade [17]. Indeed, RCEP surpassed European Union and the US-Canada-Mexico FTA in term of sheer scale. The main objectives of RCEP are trade liberalization as well as regional economic cooperation.

The RCEP dedicated chapters in addressing the protection of intellectual property, regulation of competition, e- commerce, as well as support for small and medium enterprises (SME) [3]. This pact focusses on enhancement of regional trade by lower the tariff and tariff trade barriers, set the rule of origin framework and provide trade facilitation to member countries. Furthermore, RCEP enable digitalization of trade via the increasing level of trust and confidence of SMEs as well as consumers [6],

A note to take is RCEP will not result in some massive increase in intra-regional trade in the short term since it is mainly an upgrade version of the existing ASEAN +1 agreements. Most of the tariff's items are already exempted due to other ASEAN FTAs. Moreover, countries such as 
Japan can maintain tariffs in a broad range of sectors. However, it is expected that the pact will enable a seamless supply chains throughout the 15 member nations as well as link Northeast and Southeast Asian economies closer together. With this seamless link, there will be a shift of lower end products production out of China due to the increasing operation costs and U.S.-China trade war. The shift out may benefit the countries within the same region but with a lower operation costs such as Vietnam, Thailand and Malaysia. The fears about Beijing's increasingly onerous restrictions speed up the shift out[18].

The competition in attracting investment among Southeast Asia will be intense. Malaysia will have to work harder to get those investments, especially when there are other lower-cost destinations such as Vietnam and Indonesia. For instance, a recent study showed that Indonesia can be a strong competitor for Malaysia in term of ICT content exports [19] even though the share of ICT goods is much lower in Indonesia as compare to Malaysia. Nevertheless, Malaysia experience in export, rank $25^{\text {th }}$ globally, [8] enable Malaysia have a better advantage over other countries.

With RCEP, the rule of origin is aligned for all member nations. This alignment will be facilitating the integration of RCEP participants into the same production chain. This will enable RCEP member to gain a bigger share in global value chains (GVCs) and deepen their specialization. Furthermore, with the enhancement of GVCs, RCEP members will become more interconnected and specialized in stages of production rather than in industries.

Through the GVCs, Malaysia SMEs will be able to gain skills and knowledge about conducting business across borders. A more formal and demanding environment, as a result of enhancement of GVCs, will help SMEs to work in a more formal manner. It will also upgrade SMEs' production methods, management practices, technologies and skills.

Overall, Malaysia stands to benefit from RCEP. The pact would enable Malaysia to be included in the global value chain and helps Malaysia SMEs reducing trade costs via streamline the rules and regulations of doing global trade. It will also open up a wider market access through the harmonization of technical standards and regulations, as well as economic cooperation [9]. Nevertheless, trade liberalization also means that Malaysia SMEs has to work harder and smarter in competing with businesses within the region. Malaysia policy maker can help in terms of better policy and support in attracting investments.

\section{CONCLUSIONS}

The developing and developed economies within the Asia Pacific region are integrated on an accelerated scale via RCEP. As an Asia centric FTA, the pact enables regional economic cooperation without including the largest economy in the world and the de facto leader of international trade, the United States. China is function as the de facto leader of RCEP [10]. It is not only actively involved in the increased regional economic activity but it is also grasping an opportunity to lead and shape economic growth in the Asia Pacific region.

The strengthening of economic ties in the Asia Pacific region are undoubtedly a new opportunity for all Asia countries included Malaysia. Malaysia must utilize the new trade relations between China, Japan and South Korea. Together, the three Asian countries account for about $24 \%$ of the world's economy. While these 3 countries were to capture the consumer appetite of an exploding middle class in the Asia Pacific, Malaysia can quickly be relegated to a second-tier economic power. This includes not only low value-added but also high value-added goods for which Malaysia is still competitive but facing steady vertical integration of China's value chains.

In conclusion, the RCEP reminds Malaysia that the exercise of strategic autonomy involves, first and foremost, a defence of their interests by securing access to the markets of China and the rest of the region. RCEP has facilitate constructive cooperation with the all the 15 nations in the agreement. It also facilitates Malaysia SMEs venture beyond local shores and enter new markets. With RCEP, Malaysia SMEs will be able to securing as well as share resources with other RCEP member nation and be part ot GVCs.

\section{REFERENCES}

[1] A. H. A. Rahman, "Malaysia's Free Trade Agreement," Ministry of International Trade and Industry, 2020.

https://fta.miti.gov.my/index.php/pages/view/4?mid=23 (accessed Dec. 05, 2020).

[2] S. L. Baier, Y. V. Yotov, and T. Zylkin, "On the widely differing effects of free trade agreements: Lessons from twenty years of trade integration," J. Int. Econ., vol. 116, pp. 206-226, 2019, [Online].

Available:

https://www.sciencedirect.com/science/article/abs/pii/S 0022199618304367.

[3] M. Bhadrakumar, "With RCEP, Act East policy is at the crossroads," The tribune, Nov. 2019.

[4] V. S. Seshadri, "RCEP and India: What Next?.," Indian Foreign Aff. J., vol. 14, no. 2, pp. 87-102, 2019.

[5] L. H. Guie, "Impact of RCEP on Malaysia: Gain or pain?,” The Star, Dec. 2020.

[6] D. Affizzah, A. Marikan, A. Mohammad, J. Khan, and H. Hamzah, "Malaysia and RCEP Countries: Gain or Pain?," J. Asian Sci. Res., vol. 10, no. 3, pp. 213221, 2020, [Online]. Available:

http://www.aessweb.com/pdf-files/JASR-2020-10(3)213-221.pdf. 
[7] The ASEAN Secretariat, "East Asia Summit Document Series 2005-2016," 2016. [Online]. Available: https://asean.org/wpcontent/uploads/2017/02/59.-December-2016-EastAsia-Summit-Document-Series-2005-2016.pdf.

[8] Ministry of International Trade and Industry, "RCEP - Scope," Ministry of International Trade and Industry, 2020.

https://fta.miti.gov.my/index.php/pages/view/rcep (accessed Dec. 08, 2020).

[9] C. H. Wu, "ASEAN at the Crossroads: Trap and Track between CPTPP and RCEP," J. Int. Econ. Law, vol. 23, no. 1, pp. 97-117, 2019.

[10] H. Wang, “The RCEP and Its Investment Rules: Learning from Past Chinese FTAs," Chinese J. Glob. Gov., vol. 3, no. 2, pp. 160-181, 2017.

[11] Y. Fukunaga and I. Isono, "Taking ASEAN+1 FTAs towards the RCEP: A Mapping Study. ERIA Discussion Paper Series," ERIA Discuss. Pap. Ser., 2013, [Online]. Available: http://www.eria.org/ERIADP-2013-02.pdf.

[12] L. Qiaomin and H. C. Moon, "The trade and income effects of RCEP: implications for China and Korea," ournal of Korea Trade, 2018.

[13] SME Corp. Malaysia., "Profile and Importance to the Economy." [Online]. Available:

https://www.smecorp.gov.my/index.php/en/policies/202 0-02-11-08-01-24/profile-and-importance-to-theeconomy.

[14] T. O. Mgeni, "Impact of entrepreneurial leadership style on business performance of SMEs in Tanzania.," Entrep. Organ. Manag., vol. 4, no. 2, pp. 1-9, 2015.

[15] H. Bala and F. Xuan, "Success of small and medium enterprises in Myanmar: Role of technological, organizational, and environmental factors," J. Glob. Inf. Technol. Manag., vol. 22, no. 2, pp. 100-119, 2019.

[16] I. Janita and W. K. Chong, "Barriers of b2b ebusiness adoption in Indonesian SMEs: A Literature Analysis," Procedia Comput. Sci., no. 17, pp. 571-578, 2013.

[17] The World Bank, "World Bank Open Data," 2020. https://data.worldbank.org/.
[18] UOB Global Economics \& Markets Research, "Asia Focus: RCEP To Drive Further Economic Cooperation," 2021. [Online]. Available: https://www.uobgroup.com/webresources/uobgroup/pdf/research/ASIAFocus_1q21.pdf.

[19] UOB Global Economics \& Markets Research, "Quarterly Global Outlook 1Q 2021: Malaysia," 2021. [Online]. Available: https://www.uobgroup.com/webresources/uobgroup/pdf/research/MY_1q21.pdf. 